JITA: JH. Digital Preservation.

\title{
COMPETÊNCIAS PARA A PRESERVAÇÃo E CURADORIA DIGITAIS
}

COMPETENCIES FOR PRESERVATION AND DIGITAL CURATION HABILIDADES PARA LA PRESERVACIÓN DIGITAL Y LA PRESERVACIÓN

\author{
Sonia Boeres ${ }^{1}$ \\ Murilo Bastos da Cunha ${ }^{2}$
}

\begin{abstract}
RESUMO
A Ciência da Informação, ao longo de sua existência, tem sido um campo multi e interdisciplinar, assim como tem sofrido alterações constantes, dado seu objeto de estudo: a informação. Uma vez que este elemento não é estático e está cada vez mais ligado à tecnologia da informação, tem-se visto um desafio surgir: como garantir a permanência das bibliotecas digitais? De que maneira se pode afiançar que os terabytes gerados com cada vez mais velocidade, e nos mais variados formatos, estarão disponíveis e plenamente passíveis de uso ao longo do tempo? Este é um desafio que os profissionais da Ciência da Informação estão sendo provocados a resolver, no processo das chamadas preservação e curadoria digital. Assim, esse artigo objetiva levantar as competências que o profissional da informação deverá ter para efetivar o processo de preservação e curadoria digital. O artigo discute o aparecimento das profissões (sob a ótica da Sociologia), a necessidade do trabalho para a realização do ser humano (Psicologia) e as proficiências dos que exercem o ofício da Ciência da Informação para garantir a preservação de informações digitais nas unidades de informações.
\end{abstract}

PAlaVRAS-ChaVE: Ciência da Informação. Competência profissional. Curadoria digital. Preservação digital. Profissões.

\begin{abstract}
Information Science, throughout its existence, has been a multi and interdisciplinary field, and has undergone constant change because of its object of study: information. Seen that this element is not static and is increasingly linked to information technology, we have witnessed a challenge arise: how to ensure the permanence of digital libraries? How to secure the terabytes generated with increasing speed, and in various formats, will be available and fully capable of use over time? This is a challenge that Information Science professionals are being challenged to solve in the process of so-called digital preservation and curation. Thus, this article aims to raise the skills that the information professional must have to carry out the process of preservation and digital curation. The article discusses the emergence of professions (from the perspective of Sociology), the need to work for the realization of the human being (Psychology) and proficiencies of exercising the office of Information Science to ensure the preservation of digital information in information units.
\end{abstract}

KEYWORDS: Digital Curation. Digital preservation. Information Science. Professional competencies.

Professions.

\section{RESUMEN}

La Ciencia de la Información, a lo largo de su existencia, ha sido un campo multi e interdisciplinario, y ha experimentado un cambio constante desde su objeto de estudio: la información. Una vez que este elemento no es estático y está cada vez más vinculada a la tecnología de la información, hemos visto surge un reto: ¿cómo garantizar la permanencia de las bibliotecas digitales? ¿Cómo pueden asegurar los terabytes generados con el aumento de la velocidad, y en varios formatos, estará disponible y totalmente capaz de usarse con el tiempo? Este es un reto que los profesionales de ciencias de la información tienen de resolver en el proceso de la llamada preservación digital y la preservación. Por lo tanto, este artículo tiene como objetivo aumentar las habilidades

\footnotetext{
${ }^{1}$ Doutoranda em Ciência da Informação pela UnB. Mestrado sobre políticas de preservação digital. Brasília, DF. Email: sonia.boeres@gmail.com. ORCID: http://orcid.org/0000-0003-2316-385X.

${ }^{2}$ Doutor em Biblioteconomia e Ciência da Informação (University of Michigan). Pesquisador Colaborador da Faculdade de Ciência da Informação (UnB). Brasília, DF. Email: murilobc@unb.br. ORCID: http://orcid.org/0000-0002-5725-9932.
}

Submetido em: 28/07/2016 - Aceito em: 15/08/2016 
que el profesional de la información debe tener para llevar a cabo el proceso de conservación y la preservación digital. El artículo aborda el surgimiento de profesiones (desde la perspectiva de la sociología), la necesidad de trabajar para la realización del ser humano (Psicología) y competencias de ejercer el cargo de la Ciencia de la Información para garantizar la preservación de la información digital en unidades información.

PAlabRAS Clave: Ciencias de la Información. Competencia profesional. Curaduría digital. Preservación digital. Profesiones.

\section{INTRODUÇÃO}

A Ciência da Informação (CI) envolve diversas áreas e conceitos, e seus profissionais assumem diferentes papéis em suas rotinas de trabalho, estando, o resultado qualificado, necessariamente, ligado à competência.

Há conceitos e campos que embasam a aquisição da competência profissional e pessoal. Nesse trabalho, tem-se as ligadas à CI, às habilidades pessoais (estudadas pela Psicologia) e à educação e capacitação do profissional da informação (PI), que relacionamos ao conceito de aprendizado ao longo da vida. Acrescente-se que as questões ligadas à profissão (aqui estudadas sob a ótica da Sociologia) muito contribuem fundamentando o conceito da profissão na CI. Abordaremos todos estes temas, objetivando investigar o que está em torno da competência para o profissional da CI de modo a operacionalizar a preservação e a curadoria digitais (PD).

\section{O TRABALHO E A COMPETÊNCIA NA PSICOLOGIA E NA SOCIOLOGIA}

A Psicologia estuda o ser humano nas suas interações, inclusive com o trabalho e as organizações, na subárea denominada Psicologia Organizacional e do Trabalho ou Psicologia do Trabalho e das Organizações, expressões assemelhadas, mas não de uso consensual na área (GONDIM; BORGES-ANDRADE; BASTOS, 2010, p. 84). Na literatura, ora aparece uma expressão, ora outra, representando o mesmo conceito. Aqui serão utilizadas indistintamente uma ou outra como sinônimos. A Psicologia organizacional estuda o contexto do trabalho e como o ser humano age, interage e reage com/ao trabalho, assim como suas demandas nas organizações.

Primeiramente é necessário refletir sobre a diferença entre emprego e trabalho, sob a ótica da Psicologia. O trabalho humano existe desde o começo da espécie:

[...] nas comunidades de caçadores e coletores, 8.000 anos a.C., a incipiente agricultura no Oriente Médio, na China, na Índia e no norte da África, o trabalho escravo nas civilizações antigas e a relação servil na Idade Média (...) as ideias sobre o trabalho na Antiguidade, mais referenciadas pela literatura, certamente são aquelas associadas ao pensamento greco-ateniense e às práticas escravistas no Império Romano. A literatura tem resgatado o pensamento de Platão e de Aristóteles sobre o trabalho. Tais filósofos clássicos exaltavam a ociosidade 
(ANTHONY, 1977; HOPENHAYN, 2001 apud BORGES; YAMAMOTO, 2014, p. 28).

O conceito de trabalho passou a ocupar um lugar privilegiado no espaço da reflexão teórica nos dois últimos séculos (BENDASSOLLI; BORGES-ANDRADE; MALVEZZI, 2010). Para os psicólogos Judge e Kammeyer-Mueller (2012, p. 343), como grande parte da vida é passada no trabalho, o mesmo faz parte da identidade da pessoa.

Em 1964, o termo Psicologia organizacional foi usado pela primeira vez, por Leavitt e Bass (PORTER; SCHNEIDER, 2014). Em 1990 surge o termo Psicologia Organizacional e do Trabalho (PO\&T). Outros autores utilizam a nomenclatura Psicologia do Trabalho e das Organizações (PT\&O), que podem ser definidas como subáreas de conhecimento e campo de aplicação de conhecimentos ou de intervenção (BORGES-ANDRADE; PAGOTTO, 2010). Há, também, o chamado Comportamento Organizacional (CO), que trata de temas relativos a comprometimento, estresse, aprendizagem, gênero e saúde ligado ao trabalho, questões que se tornaram dominantes na área a partir de 1998 (NEIVA; CORRADI, 2010). Porter e Schneider (2014, p. 2) utilizam os termos Psicologia Industrial e Organizacional (IO) e Comportamento Organizacional (CO) e ensinam que a parte organizacional da Psicologia surgiu a partir do pós-guerra, em 1950. Para eles não existe o campo chamado Psicologia Organizacional, e ambos preferem usar os citados termos.

Em nível internacional, Porter e Schneider (2014, p. 12) recentemente levantaram as dez áreas mais importantes para os membros da Sociedade para Psicologia Industrial e Organizacional (em inglês, SIOP), que são:

1. teste/avaliação (por exemplo, métodos de seleção, validação, preditores);

2. coaching/desenvolvimento de liderança;

3. empregados (por exemplo, recrutamento, reações de candidatos, projeto do sistema de seleção, sucessão, planejamento da força de trabalho);

4. liderança;

5. avaliação de desempenho/ feedback / gestão / estabelecimento de metas;

6. desempenho organizacional / alteração de gestão / redução;

7. metodologia de pesquisa (por exemplo, surveys);

8. cultura organizacional / clima;

9. análise de emprego / design de trabalho/ modelagem de competência (grifo nosso); 10. grupos / equipes.

No campo da Sociologia das profissões, Wilensky (1964, p. 138 apud Albernaz, 2011) fez um levantamento histórico sobre seu aparecimento. Segundo ele e Abbott (1988), o processo que leva ao aparecimento de uma profissão liga-se ao fato de os homens começarem a fazer o trabalho de período integral. Os mestres dos ofícios viram a necessidade de treinamento e prática e abriram escolas, isto antes dos cursos em universidades. Daí Wilensky aponta surgir a questão da competência como fator importante para as profissões. 
Para Goode (1957, p. 194 apud Albernaz, 2011) cada profissão é uma comunidade sem local físico. Com o tempo, a proteção legal do monopólio das competências aparece, e um código de ética é adotado.

Abbott (1988) é um autor clássico da área de Sociologia das profissões, segundo Mueller (2004), Walter (2008), Silva (2009) e Albernaz (2011). Ele divide o trabalho profissional em três etapas: classificar o problema, refletir e argumentar sobre ele, e agir para solucioná-lo, ou seja, efetuar o diagnóstico, inferência e tratamento. A condição que distingue profissão de ocupação é existir o conhecimento abstrato de características acadêmicas, responsabilidade de pesquisadores e professores.

Mueller (2004, p. 26) e Parson (1939, p. 466 apud ALBERNAZ, 2011, p. 127) mencionam os seis atributos que caracterizam uma profissão:

1. corpo de conhecimento especializado, abstrato e sistematizado;

2. autonomia no exercício profissional;

3. capacidade de autorregularão;

4. existência de procedimentos de credenciamento;

5. exercício da autoridade sobre clientes;

6. publicação de um código de ética.

\section{O PROFissional da informaÇÃo, a PRESERVAÇÃo e A CURADORIA DIGITAIS}

Analisando o contexto do profissional da informação (PI) da CI e sua atuação na preservação digital, o exame da literatura mostrou que o PI é e está cada vez mais multifacetado e multidisciplinar e, para isto, deve procurar manter-se atualizado, inovador e criativo. O profissional, por mais que não tenha preferência pela atuação na área tecnológica, não pode fechar os olhos ou resistir ao aprendizado/letramento digital.

O que define um profissional da informação? De modo resumido, e baseado na literatura, o mesmo é aquele capaz de atuar em espaços onde o ciclo da informação acontece, vindo de múltiplas formações, porém com o cerne na pós-graduação em CI. É o profissional ao mesmo tempo mediador, e facilitador das informações para os usuários, físicos ou virtuais.

Concordamos com a afirmação de Mueller (1989, p. 63), quando alega que a maior eficiência e relevância do papel social do PI viria de sua associação com outros profissionais que também visam à satisfação de necessidades individuais de informação. No contexto do profissional, para trabalhar com preservação e curadoria de informação digital, o que é muito atual, crê-se que um tipo apenas de profissional não será suficiente e completo para bem desempenhar suas funções no conjunto da profissão, e do mundo digital, que requer múltiplas formações e competências, aliadas especialmente às dos profissionais da informática. 
Quais as competências necessárias para equipes de profissionais de informação fazerem preservação e curadoria digitais? O PI possui uma formação teórica rica, mas ainda carente de atualização na área tecnológica, especialmente no que tange o digital. Esta área é das que mais se sobressaem na profissão atualmente, dada a evolução da biblioteca digital, e a inserção dos documentos virtuais nos acervos das unidades de informação. A literatura tem mostrado ser imprescindível a capacitação ao longo do tempo (GAMA, 2013). A competência por meio de estudos continuados, por toda a vida profissional, é que pode ajudar a garantir que o PI não se defase e se mantenha competente no mercado de trabalho, uma vez que as tecnologias da informação estão em constante e frenética mudança (BRANDÃO, 2009). Se antes uma máxima da comunicação científica era publish or perish, poderíamos dizer que agora é update or perish.

Investigando a literatura, notou-se que muitos autores da área se limitavam a dar respostas demasiado genéricas sobre o "novo" PI e sua atuação na preservação e na curadoria digitais. Aqui procuramos analisá-lo criticamente, trazendo temas atuais e novas visões de mundo da profissão.

\section{A PRESERVAÇÃo E A CURAdORIA digItAL}

Para Hedstrom (1998, p.189), a preservação digital é efetuar “[...] planejamento, alocação de recursos e aplicação de métodos e tecnologias para assegurar que a informação digital de valor contínuo permaneça acessível e utilizável [...]”.

Para Márdero Arellano (2004, p. 43), a PD é um dos grandes desafios do século XXI, inclusive no tocante à mídia de armazenamento, que aparece no mercado e em seguida desaparece. Ferreira (2006) define preservação digital como sendo a capacidade de garantir que a informação digital permaneça acessível e com qualidade de autenticidade para que possa, no futuro, ser interpretada numa plataforma tecnológica diferente daquela utilizada em sua criação. A preservação e a gestão de objetos digitais no Brasil deve ser uma prioridade estratégica nas empresas, inclusive para a qualidade dos seus serviços. É um processo complexo, envolvendo muitas variáveis que obrigam ter-se planejamento e execução detalhados.

Na página do sistema Portico (2015) há a definição de PD como uma série de políticas, e atividades de gestão, necessárias para assegurar a duradoura usabilidade, autenticidade, descoberta e acessibilidade dos conteúdos em longo prazo.

Segundo Rosenthal et al. (2005) o objetivo do sistema de PD é que a informação que ele contém permaneça acessível ao usuário por longo do tempo. A propósito, para o OAIS (CCSDS, 2012, p. 1) longo prazo é um período de tempo longo o suficiente para se ter ideia 
dos impactos das mudanças tecnológicas, incluindo suporte a novas mídias e formatos de dados da informação que está sendo mantida no modelo OAIS. É um futuro indefinido.

Já em 2008, Márdero Arellano também se referiu aos três pontos básicos de uma PD: a autenticidade, confiabilidade e integridade. Resumiu como sendo a autenticidade dos dados a certeza de quem é seu criador (p. 135), a confiabilidade, ligada à certificação, segurança dos dados digitais (p. 277), e a integridade, a inteireza do conteúdo, a sua não alteração ou modificação para permitir o acesso continuado.

Os estudos sobre curadoria digital, para Tibbo, Hank e Lee (2008), começaram a aparecer entre 2007 e 2008, mas muito antes disto o tema já era questionado. Segundo Sayão e Sales (2012), curadoria digital é a gestão de dados de pesquisa desde o seu planejamento, assegurando a sua preservação por longo prazo, descoberta, interpretação e reuso. Um conceito ampliado da preservação digital, pois envolve desde as etapas do planejamento até o reuso dos dados de pesquisa, mas ainda é novo e com relativamente pouco trabalhos. A PD já está com um cenário mais definido, ainda há quem misture os dois conceitos.

Para a Clatin et al. (2014), a definição de curadoria digital envolve

(...) o conceito global que inclui todos os aspectos do trabalho sobre os bens culturais digitais, digitalizados e os nascidos digitais: desde a entrada do documento, à descrição dos dados, armazenamento, disseminação e preservação a longo prazo" (tradução nossa).

Note-se que embora preservação e curadoria tenham muitas semelhanças, a curadoria envolve um processo mais abrangente, pois abarca a preservação desde o momento da criação dos dados. Isto engloba um amplo processo que altera o uso dos dados de pesquisa como vinha sendo feito até o momento. Dados originais e inéditos de pesquisadores, e os oriundos de pesquisas, como as relativas ao $e$-science, passam a ter outros valores agregados, inclusive o de permitir que seus dados brutos possam ser reaproveitados por outros pesquisadores. Quando os pesquisadores, via Dataverse ou outro sistema integrado de dados, oferecem acesso a eles, estes podem reutilizar, com ética, os dados brutos para fazer diferentes análises e conclusões. Aparece aqui uma ideia ainda pouco observada: a do reuso "ecológico" dos dados brutos. Poucos cogitam que o processo de preservação e de curadoria de dados também reflete o cuidado com o meio ambiente. Versões digitais podem levar a menos descartes e custos (de papel, de impressão, de deslocamentos para coleta de dados, compartilhamento dos equipamentos usados para coletar dados, entre outros) e na otimização do uso dos dados originais (uma coleta geraria várias fontes para análises e resultados). Assim, os custos envolvidos na coleta dos dados pelo primeiro pesquisador ficam muito diluídos, se compartilhados com outros pesquisadores, que virão a reutilizá-los daí em diante.

O que a literatura aponta é que, no Brasil, onde os estudos estão mais iniciais, a nomenclatura que define o amplo processo de tratamento de dados digitais é muito variada, e ainda não uniformizada nem padronizada, abaixo traremos exemplos. Termos, em português e inglês, como preservação digital, curadoria digital, gestão de dados digitais, e Science, entre 
outros, assim como os respectivos títulos para tais profissionais, ainda são usados indistintamente por alguns. Para exemplificar, listamos alguns estudos sobre competências para profissionais ligados à preservação de dados, onde apresentamos o uso de diferentes termos para tratar da mesma ideia. A expressão curador digital é usada por Abbott (2008) e por Kim, Warga, Moen (2013, p. 68, 78), data scientists, por Palmer; Blake; Allard (2012); digital curator, data curator, data manager, eScience professionals, por Kim, Warga, Moen (2013, p. 68, 78), o que mostra a ainda "novidade" do fenômeno de resguardar dados digitais e a falta de unificação dos termos.

\section{O QUE É COMPETÊNCIA?}

Definiremos competência abordando seus variados aspectos. Gilbert (1978 apud BRANDÃO, 2009) ressalta que a competência expressa o desempenho ou comportamento da pessoa no trabalho. Sua proposta sofreu influência do movimento S-R, segundo o qual a compreensão do comportamento deve estar vinculada à investigação das relações entre estímulos (S) e respostas (R).

Mais tarde, Durand (2000) veio a levantar os componentes, ou elementos, da competência: conhecimentos, habilidades e atitudes do indivíduo. Sua proposta parece ter sido influenciada pelo movimento S-O-R, segundo o qual essas afinidades precisam considerar o que ocorre no indivíduo $(\mathrm{O})$, que mediaria as relações entre estímulos (S) e respostas (R). As abordagens cognitivistas, de acordo com Brandão e Borges-Andrade (2007), se baseiam nesta teoria e pressupõem que a interação da pessoa com o ambiente resulta em processos cognitivos ou na aquisição de conhecimentos, habilidades e atitudes. Mais tarde Brandão (2009, p. 11) reafirma o que disse em 2007, chamando de Três Dimensões da competência: conhecimento, habilidade, atitude.

Para Valentim (2002, p. 122) competências profissionais são o “(...) conjunto das habilidades, as destrezas, as atitudes e os conhecimentos teórico-práticos necessários para cumprir uma função especializada, de um modo socialmente reconhecido e aceitável". Para ela, no contexto do trabalho de CI, existem dois tipos de competências, as técnico-científicas e as gerenciais. As técnico-científicas pressupõem:

- $\quad$ executar o processamento de documentos em distintos suportes, em unidades, sistemas e serviços de informação;

- $\quad$ armazenar e recuperar informação guardada em qualquer meio para os usuários de unidades, serviços e sistemas de informação;

- utilizar e disseminar fontes, produtos e serviços de informação em diferentes suportes;

- $\quad$ executar procedimentos automatizados;

- $\quad$ planejar e construir redes de informação. 
Segundo Freitas e Brandão (2006 apud BRANDÃO, 2009), de acordo com os enfoques cognitivistas, a competência é a união dos conceitos de conhecimentos, habilidades e atitudes, divulgados pelo desempenho profissional em um contexto organizacional, agregando valor a pessoas e organizações.

As competências profissionais mostram-se quando as pessoas agem nas situações com as quais se deparam nas organizações e, de acordo com Zarifian (1999), unem atributos individuais e a estratégia traçada pela organização. Elas agregam valor econômico ou social a indivíduos e organizações, por contribuírem para a execução de objetivos organizacionais, expressando o reconhecimento social sobre a capacidade de pessoas, equipes e instituições.

\section{COMPETÊNCIA E APRENDIZADO AO LONGO DA VIDA}

A competência também é fruto do que o psicólogo Dewey (1979) chamou de pensamento reflexivo e crítico, gerando pessoas interessadas em aprender a aprender, prática fundamentada em suas experiências e aquisições de conhecimento ao longo de suas vidas. Segundo ele, é a síntese das experiências de vida que cada profissional carrega, produzindo um saber fazer consciente.

No mundo físico, a mensagem é enviada do emissor ao receptor, e uma das formas de se saber que o canal não apresentou ruído, ou seja, que a mensagem foi recebida e entendida, é quando ela é respondida. Já no mundo virtual a mensagem é enviada e instantaneamente recebida pelos sujeitos sociais (receptores), que respondem, ou não, e interagem em tempo real, transformando radicalmente a relação entre os dois mundos, utilizando diferentes plataformas tecnológicas. A competência tecnológica pode não só ajudar a fazer os indivíduos mais produtivos economicamente, mas também atender aos que postulam o desenvolvimento da capacidade analítica e crítica do cidadão.

Com tantos saberes disponíveis em meio virtual, uma questão que não pode ser esquecida é a preservação de todo este conteúdo disponível no meio digital. Ignorar isto é colocar em risco de perda este conteúdo, a cada minuto, disponibilizado nas bases de dados digitais.

O PI que intenciona buscar e aprimorar sua competência profissional no mundo digital deve procurar uma maneira de dar sentido às novas formas de comunicação, divulgação e apresentação dos conteúdos digitais. Hoje ele tem que lidar com a informação em diversos suportes (texto, imagens, sons, filmes, entre outros) no processo de PD, suportes estes cada vez mais diversificados.

Não basta aprender, ter experiência, buscar se reciclar, é necessário manter-se atualizado ao longo da vida. Albernaz (2011, p. 83) assegura ser urgente repensar o perfil do 
PI, que tem expandido o escopo de suas atividades e gerado novos significados, bem como vê seu espaço profissional crescer, absorvendo novas funções. A autora tem mostrado ser imprescindível a capacitação ao longo do tempo. A habilitação por meio de estudos continuados, por toda a vida profissional, é que pode ajudar a garantir que o PI não se defase e se mantenha competente no mercado de trabalho, uma vez que as tecnologias da informação estão em constante e frenética mudança.

\section{COMPETÊNCIAS PARA A PRESERVAÇÃo E CURADORIA dA INFORMAÇÃo DIGITAL}

No contexto da CI, tendo à frente o pensamento de Otlet e La Fontaine, com o ideal de organização universal do conhecimento, a internet também acrescenta muito ao conceito de disponibilizar conteúdos universalmente reunidos, classificados e organizados, mas que, atualmente, podem correr o risco de não permanecerem com o acesso disponível. $\mathrm{Na}$ totalidade dos conteúdos digitais, organizar este tipo de informação e prevenir contra sua perda e adulteração no conteúdo, são fatores de grande relevância para o estudo da PD.

A PD envolve o garantir que a informação digital permaneça acessível, com autenticidade, integridade e confiabilidade, para que possa, futuramente, ser completamente acessada, interpretada e utilizada, inclusive numa plataforma tecnológica diferente daquela utilizada em sua criação. Para ser sustentável, no sentido de ser efetivada e mantida em funcionamento, deve ser uma prioridade estratégica nas empresas, envolvendo iniciativas de boa gestão e acordos entre o responsável pela unidade de informação junto com os gestores da instituição onde a iniciativa está acontecendo.

Preservar digitalmente é conservar vivos os instrumentos comprobatórios da instituição, de valor legal e político, inclusive para auditorias. É ter a preocupação e o cuidado de manter viva a memória coletiva, os documentos que constituem a história dos lugares, das pessoas, dos processos e o passar do tempo, bem como dos procedimentos da instituição.

Quanto ao instrumento de política de PD, ele é vital na gestão deste processo, e o de uma biblioteca digital deve ser mais abrangente e detalhado do que o de um repositório institucional, por oferecer uma gama maior de serviços que os repositórios.

$\mathrm{O}$ que temos hoje em relação à tecnologia para PD provavelmente será considerado ruim e inadequado no futuro, mas atualmente é algo novo, é o que se conhece, é o que foi possível idealizar. Os softwares de PD têm uma missão a longo prazo, mas devem ser plenamente utilizáveis no presente, até porque a tecnologia ainda vai mudar muito. Os requisitos na escolha dos softwares para PD dependem de cada projeto a ser implantado, do 
tipo de arquivo a ser preservado, do orçamento da instituição e do objetivo da preservação em si.

É importante lembrar que algumas decisões sobre PD, necessariamente, são tomadas sob condições de incertezas quanto às mudanças tecnológicas, políticas (de governo e da instituição), prioridades de investimento no projeto e demandas da sociedade. Tudo isto pode mudar durante o curso do projeto de $\mathrm{PD}$, mas práticas devem ser desenvolvidas para antecipar ou resolver algumas destas incertezas, de modo a não colocar em risco a viabilidade do projeto.

Para Davenport e Prusack (1998 apud FARIA; CASTRO FILHO, 2014) bons profissionais de informação digital necessitam de habilidades hard (conhecimento estruturado, qualificações técnicas e experiência profissional) e atributos soft (senso dos aspectos culturais, políticos e pessoais do conhecimento).

Segundo Vendrell e Miranda (1999 apud FARIA, 2015) as competências necessárias para o PI são de seis tipos: competência intelectual, prática, interativa, social, ética e estética. Em dissertação, Faria (2015, p. 49) cita as competências mais importantes demandadas pelo mercado de trabalho, no âmbito da CI:

a) conhecimento do ambiente de negócios da informação;

b) capacidade de trabalhar em grupo;

c) distinção e localização de informações relevantes e relevância nas informações;

d) o domínio na utilização de equipamentos eletrônicos e na operação de sistemas ou softwares específicos;

e) conhecimento de bases de dados;

f) familiaridade na administração de info-business;

g) embasamento teórico e prático sobre o funcionamento das organizações virtuais de informação;

h) domínio da lógica dos sistemas de indexação e webfinders;

i) excelência na comunicação oral e escrita;

j) conhecimento da infraestrutura e serviços de informação;

k) ter flexibilidade e polivalência;

1) atualização profissional constante;

m) capacidade de entender e gerenciar episódios de diferentes naturezas e aplicações;

n) habilidade na identificação de clientes e fornecedores e

o) habilidade na identificação de parceiros.

Valentim (2002) explica que as competências sociais e políticas se ligam às atitudes, ao querer fazer, à comunicação e à expressão; já as competências gerenciais e técnicocientíficas se relacionam aos procedimentos. Então estas últimas compreendem as habilidades necessárias para o desempenho profissional. Todas demandam por conhecimentos, o saber porque fazer. Ela destaca que as habilidades de cada competência não 
se esgotam em si, mas foram desmembradas para melhor entendimento do que seria cada uma delas.

O ciclo ou fluxo do documento é o controle e monitoramento do registro (documento) na organização, é o trâmite do documento (BUENO, 2013, p. 17). Ele envolve diversos procedimentos nas diferentes etapas do ciclo documental (CUNHA, 2009), das quais destacaremos as que julgamos imprescindíveis para o documento digital e o papel do PI nelas:

- Seleção e processamento de documentos: o PI deve ter íntima relação com as normas de tratamento da informação, assim como saber conhecer os padrões, formatos e protocolos da web, que facilitam o crescimento das redes. Tem que conhecer as regras para descrição, curadoria e preservação dos objetos digitais, o que inclui a atribuição de etiquetas (tags). O PI pode aproveitar (com críticas) as tags socialmente atribuídas, movimento conhecido como etiquetagem coletiva ou folksonomia (DZIEKANIAK; PACHECO; KERN, 2011 apud FARIA, 2015). Também deve saber como e onde os conteúdos da sua unidade de informação serão armazenados e recuperados, e como será feita a intercomunicação entre os sistemas envolvidos com a entrada e recuperação dos dados da base daquela unidade.

- Desenvolvimento de coleções, seleção e aquisição: no passado o grande responsável por esta tarefa era o PI, e quase que exclusivamente ele. Atualmente tal competência tem mudado, e a responsabilidade está cada vez mais dividida entre o PI e o usuário. Um exemplo é o uso dos e-books nas organizações. Dependendo da licença que o PI disponibiliza para seu uso, poderá já não caber a formação da coleção ao PI, como era, mas também ao usuário, que poderá escolher o material a que quer ter acesso, baixando os livros dos sítios que tais licenças permitem. Assim, o usuário não apenas usa os serviços oferecidos, mas também interage, sugere e influencia as decisões das unidades de informação. Isto faz com que o PI questione diariamente seu novo papel no mundo digital, não por ele não deter a prioridade nesta escolha, mas porque sua responsabilidade fica aumentada no sentido de que o acervo será composto pelas preferencias do público que usa, e não apenas pelo que o PI tecnicamente decide adquirir.

- Controle bibliográfico: os procedimentos de catalogação e classificação passaram a ter cada vez mais pontos de acesso, ainda mais se passarem pelo processo de etiquetagem coletiva, as buscas nas bases estão disponibilizando mais itens (em termos numéricos e em profundidade de pesquisas) com a procura cada vez maior dos artifícios das ontologias. A área da Linguística está se aproximando cada vez mais da CI, de modo a permitir a recuperação da informação via FRBR, AACR3 e RDA, por exemplo. Com o FRBR (Functional Requirements for Bibliographic Records) modelo de representação e abstração da realidade, a informação tem estado mais organizada, agrupada e buscada de forma diferenciada. O AACR3 (Anglo American Cataloguing Rules 3) virou o RDA 
(Resource Description and Access) devido a tantas mudanças que ocorreram. E o RDA, código de catalogação que contempla o que apareceu na web, infere-se, será o novo padrão para descrição e acesso a recursos, projetado para o mundo digital (LIMA, 2015). Consequentemente, a inserção dos metadados dos documentos está diferenciada, objetivando a curadoria, gestão, recuperação e preservação do documento digital.

- Referência digital: a atividade busca prover serviços a usuários remotos, por e-mail ou outros tipos de contato virtual, modificando em muito a interação usuáriobiblioteca. Para Bazin, (In: ACCART, 2012, p. ix, x), a função da referência mescla a competência intelectual, o conhecimento técnico e a relação com o usuário. O que é o serviço de referência físico, hoje, pode ser relacionado às redes de conhecimento virtuais, porém, segundo Bazin, um paradoxo surge: quanto mais os serviços se automatizam, mais o componente humano ganhará importância no que tem de pessoal. Inferimos que as competências ligadas à empatia, às habilidades interpessoais, ao saber lidar com pessoas e conseguir se comunicar se sobressairão mais, para amenizar a impessoalidade da internet.

- Avaliação: a análise dos produtos e serviços oferecidos em meio digital são cada vez mais globais, ou, como diria Chaim (In: AMARAL, 2007, p. 97), transnacionais. Para ele, a interatividade, a personalização, interdependência das organizações e postura globalizada fazem parte do marketing da internet. Tanto a etapa de referência digital como a de avaliação devem estar envolvidas com o processo de marketing da informação. Certamente um produto informacional que sofreu muita propaganda terá testes, usos e avaliações diferentes de um que ficou disponível de modo mais discreto. Nem tudo o que as unidades de informações oferecem interessa a todos os usuários e nem chega ao conhecimento deles. Mostrar e avaliar o interesse é competência importante dos PI.

Tem-se ainda o trabalho de Allard, Mack e Feltner-Reichert (2005), que focaram suas atenções nos papéis dos bibliotecários de Repositórios Institucionais (RI), que necessitam de PD de seu conteúdo. Eles coletam, preservam e distribuem materiais digitais neles produzidos. Por meio da análise da literatura, os autores levantaram seis áreas de conhecimentos e habilidades:

1. entender de software;

2. saber fazer planejamento e gestão de projetos;

3. definir de coleção;

4. elaborar guia de metadados (Metadata guidance);

5. revisar as submissão (dos repositórios institucionais);

6. dar treinamento aos autores.

O North American Serials Interest Group (NORTH AMERICAN, 2013) definiu as competências para profissionais de recursos eletrônicos. O NASIG Core Competencies Task Force (NCCTF) sugere que elas sejam usadas junto com o direcionamento da American Library Association's Core Competences of Librarianship. O documento separa em blocos 
diversas competências do PI eletrônico, elas envolveriam: o ciclo de vida de recursos eletrônicos (NORTH AMERICAN, 2013, p. 1), tecnologia (p. 2), pesquisa e acesso (p. 4), comunicação efetiva (p. 5), supervisão e gestão (p. 6), tendências e desenvolvimento pessoal e qualidades pessoais (p. 7).

Um resumo de tais competências seria:

a) ter experiência. Trabalhar em bibliotecas digitais não contempla, em princípio, profissionais iniciantes, recém-formados, e os empregadores tendem a associar anos de experiência com competências que se identificam em anúncios de emprego;

b) saber gerir o orçamento de recursos eletrônicos, inclusive para obter termos de licenciamento menos restritivos durante as negociações de licença, entre o editor e o fornecedor, afinal, fazer curadoria e preservação digital é caro;

c) capacidade de aplicar os princípios da organização, representação do conhecimento e da informação registrada e, especialmente, conhecer sobre metadados de preservação;

d) possuir conhecimentos e habilidades tecnológicas, conhecimentos teóricos e práticos das estruturas de hardware e software subjacentes à prestação de acesso aos recursos eletrônicos e sua inter-relação;

e) ter conhecimento conceitual e prático do hardware computacional e dos dispositivos móveis usados para acessar informação eletrônica, e seus sistemas operacionais;

f) saber sobre tecnologias de redes (com ou sem fio), normas, protocolos e estruturas como o Z39.50, o Open Archives Initiative - Protocol for Metadata Harvesting (OAI-PMH), as técnicas emergentes de preservação digital e tecnologia, computação em rede, uso de tecnologias e de suas ferramentas de preservação digital nos produtos e serviços informacionais;

g) ter conhecimento de arquiteturas de sistemas, capacidade, opções de suporte, entre outros, para sistemas de bibliotecas envolvidos no acesso e preservação dos recursos eletrônicos.

Fraser-Arnott (2013, p. 6) também fez um estudo de análise de conteúdo de 110 anúncios de emprego, coletando 1.336 competências para profissionais de Biblioteconomia e Ciência da Informação (em inglês, Library and Information Science, LIS professionals). Dois grupos de anúncios foram usados para este artigo: o Quadros de emprego da LIS (LIStargeted job boards) e os anúncios de emprego internos ao governo ao Canadá (Government of Canada internal job postings). O resultado mostrou que:

- $\quad$ quanto ao empregador: a maioria das vagas era para bibliotecas acadêmicas ( $30 \%$, ou 33 postagens) ou públicas ( $21 \%$, ou 31 postagens);

- $\quad$ requisitos educacionais: $50 \%$ pedia mestrado em biblioteconomia ou CI ou grau equivalente, o segundo lugar era para quem tivesse doutorado (16\%), as ofertas seguintes eram para técnicos $(12 \%)$, graduação $(11 \%)$ e outros $(11 \%)$; 
- os grupos de competências formados foram: as relativas a conhecimento e experiência, trabalho específico de biblioteca, competências de tecnologia da informação e habilidades transferíveis.

A partir destas informações anteriores infere-se que, entre as bibliotecas, as que mais necessitam de PI especializados em informação digital são as bibliotecas universitárias, o que é coerente. É de lá que sai boa parte das pesquisas do país, o que demanda pesquisadores de ponta com estudos também assim.

A formação de tais profissionais requer que sejam especializados e que tenham buscado cursos específicos para isto (mestrado, doutorado). Conhecimento, experiência, instrução própria em bibliotecas e habilidades tecnológicas são vitais para os PI.

Tabela 1. Competências totais requeridas, da Library job board advertisements

\begin{tabular}{|c|c|c|}
\hline Grupo de competência & $\begin{array}{c}\text { Referência } \\
(n=1336)\end{array}$ & $\begin{array}{l}\text { Percentagem do total } \\
\text { das competências }\end{array}$ \\
\hline 1. Conhecimento e experiência & 194 & $14.5 \%$ \\
\hline 2. Comunicação & 164 & $12.3 \%$ \\
\hline 3. Qualidades pessoais & 156 & $11.7 \%$ \\
\hline 4. Tecnologia da informação & 147 & $11 \%$ \\
\hline 5. Gestão e supervisão & 120 & $9 \%$ \\
\hline $\begin{array}{l}\text { 6. Trabalho em equipe e habilidades } \\
\text { interpessoais }\end{array}$ & 114 & $8.5 \%$ \\
\hline 7. Habilidades organizacionais & 82 & $6.1 \%$ \\
\hline 8. Ensino, treinamento e instrução & 63 & $4.7 \%$ \\
\hline 9. Catalogação e Metadados & 60 & $4.5 \%$ \\
\hline 10. Pesquisa e referência & 59 & $4.4 \%$ \\
\hline 11. Resolução de problema e solução & 52 & $3.9 \%$ \\
\hline 12. Serviço ao usuário & 46 & $3.4 \%$ \\
\hline 13. Entrega de programa e gestão & 30 & $0.2 \%$ \\
\hline 14. Gestão de coleção/Gestão & 27 & $2 \%$ \\
\hline
\end{tabular}




\begin{tabular}{|c|c|c|}
\hline 15. Desenvolvimento profissional & 17 & $0.13 \%$ \\
\hline $\begin{array}{c}\text { 16. Marketing e promoção de } \\
\text { biblioteca }\end{array}$ & 5 & $0.04 \%$ \\
\hline
\end{tabular}

Fonte: Fraser-Arnott (2013, p. 6)

Observe-se na tabela 1, que destas 16 competências levantadas, os dados levam a crer que o que o mercado americano quer é PI com habilidades pessoais (grupo 1,2,3,6,11,), tecnológicas $(4,13$,$) , atualização e treinamento (8,15)$, com domínio técnico $(9,10,12,14$, 16).

Tabela 2. Competências totais requeridas, Government of Canada Job Advertisements

\begin{tabular}{|c|c|c|}
\hline Grupo de competência & $\begin{array}{c}\text { Referência } \\
(\mathbf{n = 1 5 2 2})\end{array}$ & $\begin{array}{c}\text { Percentagem do total } \\
\text { das competências }\end{array}$ \\
\hline 1. Conhecimento e experiência & 244 & $16 \%$ \\
\hline 2. Comunicações & 178 & $11.7 \%$ \\
\hline 3. $\begin{array}{l}\text { Tecnologia da Informação / Gestão } \\
\text { da Informação / Gestão de registros }\end{array}$ & 172 & $9.3 \%$ \\
\hline 4. $\begin{array}{l}\text { Trabalho em equipe e habilidades } \\
\text { interpessoais }\end{array}$ & 141 & $8.6 \%$ \\
\hline 5. Qualidades pessoais & 131 & $7.3 \%$ \\
\hline 6. Pesquisa, análise e resolução de \\
problema
\end{tabular}

Fonte: Fraser-Arnott (2013, p. 7) 
A pesquisa canadense, constante da tabela 2, comparada à americana, também levanta competências pessoais (grupo 1,2,4, 5), tecnológicas (3, 10); não lista especificamente competências ligadas à atualização, treinamento e domínio técnico; e acrescenta habilidades específicas de ordem financeira (8), organizacional $(9,13)$ e gestão de RH (12).

Note-se que ambas as pesquisas levantam competências de cunho pessoal, justificando nosso estudo via Psicologia das organizações. Também elenca competências genéricas e menos ainda diretamente ligadas aos profissionais digitais, corroborando afirmarmos que o levantamento almejado na literatura é vagamente explorado, daí porque este artigo ser inovador e importante para a CI.

Duas habilidades de tecnologia da informação foram incluídas nos anúncios entre as dez competências mais solicitadas (FRASER-ARNOTT, 2013, p.9): "Tecnologias Inovadoras, Aplicações e Media Social" e "Softwares de Negócios" (Microsoft Office). A conexão entre a gestão da informação e a tecnologia da informação era forte nos anúncios do Governo do Canadá: a maioria dos postos de trabalho, nesta lista, que pediram background educacional ligado à gestão da informação incluía principalmente requisitos de competência em tecnologia da informação.

Embora as habilidades de tecnologia da informação fossem um grupo de competência significativo para a lista do Governo do Canadá, nenhuma competência, específica, relacionada à tecnologia em si, apareceu entre as dez competências mais solicitadas para esta amostra (FRASER-ARNOTT, 2013, p. 9).

No mesmo ano, Kim, Warga, Moen (2013) também realizaram uma pesquisa e identificaram as competências para o curador digital. Para eles, a curadoria digital tem tido um papel cada vez mais urgente e importante no ambiente de informação. Assim, há uma necessidade de identificar um conjunto de competências para os profissionais desta área em crescimento. Como parte de um projeto de desenvolvimento de currículo, financiado pelo U.S. Institute of Museum and Library Services, eles coletaram, de diversas fontes, um total de 173 anúncios de emprego, publicados entre outubro de 2011 e abril de 2012, para levantar os diversos tipos de competências profissionais desejáveis no campo da curadoria digital, em toda a América do Norte. Foram examinados e analisados: titulação, posição, tipos de instituição e localização, formação educacional, experiência, conhecimentos, competências e deveres. Os resultados da pesquisa mostraram que tais profissionais são caracterizados por uma complexa e rica interação de várias habilidades e conhecimentos, e que há exigências emergentes por uma mão de obra qualificada no campo da curadoria digital.

Lefurgy (2013) e Kim, Warga, Moen (2012, p. 3-4; 2013, p. 77, 78), que também pesquisaram sobre competências para profissionais na área digital em anúncios de jornais especializados, destacam os principais achados: 
- $58 \%$ dos anúncios queria candidatos preparados para trabalhar em um ambiente de tecnologia de informação intensiva (information technology intensive environment) e não específico. A pesquisa levantou como possíveis locais de trabalho bibliotecas, museus e hospitais, entre outros;

- $66 \%$ pediam candidatos com experiência de trabalho em bibliotecas ou arquivos. Destes, 18 anúncios preferiam pessoas com experiência em aquisição, curadoria, preservação e gestão de conteúdo digital; 9 pediam experiência no trabalho com dados de pesquisa; 6 requeriam experiência em repositório institucional e 3 almejavam pessoas com experiência em padrões e técnicas ligados à tecnologia de biblioteca digital;

- $58 \%$ especificavam o tempo de experiência profissional desejado: $13 \%$, ao menos um ano; 27\%, mínimo de 2 anos; 20\%, mínimo de 3 anos; 2 posições administrativas pediam ao menos 8 anos de experiência relevante; o número médio foi de 2.7 anos de experiência;

- $55 \%$ requeriam conhecimento sobre padrões como Dublin Core, METS (Metadata Encoding \& Transmission Standard) e MODS (Metadata Object Description Standard) dos candidatos aos cargos;

- $45 \%$ dos anúncios pediam habilidades para gestão de projetos (project management skills);

- $85 \%$ das postagens pedia candidatos com grau de mestre credenciamento pela ALA;

- $28 \%$ pedia mestrado em outras áreas que não a CI;

- Genericamente se solicitava ter tanto habilidades práticas (experiência), como técnicas.

Sem dúvida, a competência dos PI para trabalharem com PD passa pela análise constante da competência gerencial do gestor e das habilidades da equipe, que cada vez mais deverá contar com pessoal especializado. Um tema pouco abordado nas pesquisas, porém vital, são os aspectos jurídicos envolvidos na curadoria e na preservação da informação digital que é o direito autoral. Questões legais ligadas, por exemplo, a compras na web, já estão com suas normas definidas, mas no que se refere a PD, não. No Brasil contamos com uma legislação defasada e muito restritiva. Também é necessário avaliar as implicações econômicas dos projetos de preservação e curadoria digitais, que são caros, portanto, devem ter uma avaliação técnica afiada sobre a sustentabilidade (manutenção) do projeto, ou ele falhará. A elaboração de política de PD, baseada na missão da organização é um documento importante como norte a ser seguido. 


\section{CONCLUSÕES}

Este artigo teve como objetivos identificar as competências profissionais nos serviços de informação dos que trabalham na área de curadoria e preservação digital; e identificar as competências tecnológicas dos profissionais para trabalhar com estas. Pelos dados colhidos e comentados cremos tê-los atingido como veremos a seguir.

Tema de grande importância é o estudo de competência profissional e tecnológica para profissionais que fazem preservação e curadoria dos dados virtuais. $\mathrm{O}$ assunto deve ser inserido nos estudos desenvolvidos no âmbito das bibliotecas digitais, entidade responsável pela proteção e garantia da manutenção da informação ali depositada em meio digital.

Apesar do tema PD já estar bem explorado na literatura nacional e internacional, a curadoria de dados ainda é assunto relativamente novo no Brasil. Além disso, algumas instituições ainda carecem de direcionamentos práticos sobre como operacionalizar políticas e rotinas direcionadas para se preservar digitalmente itens, algumas vezes ficando a cargo do backup a "iniciativa" para preservação. Baseado na literatura, infere-se que as bibliotecas digitais e a área de CI como um todo devem capacitar melhor seus profissionais para esta finalidade específica.

Pode-se dizer que competência se relaciona a funcionalidade, é colocar em prática uma base solida de conhecimentos factuais. É entender os fatos e ideias no contexto da estrutura conceitual e organizar o conhecimento para facilitar sua recuperação e aplicação. Definir as competências do profissional da informação digital não é tão fácil ou simples, pois, como mostra a literatura, desde, aproximadamente, o ano de 2008, ou seja, há menos de sete anos, têm surgido trabalhos sobre o assunto, o que se tinha até então era conteúdo extraído da área mais geral, Administração, que tradicionalmente estuda o assunto sob seu ponto de vista, não especificando para o contexto digital.

Quanto ao primeiro objetivo, identificar as competências profissionais nos serviços de informação dos que trabalham na área de preservação e curadoria digitais, a literatura citada mostrou que para ser competente é importante ter experiência profissional. Uma pesquisa de mercado sobre anúncios de emprego constatou que $66 \%$ pediam experiência. Nesta mesma linha de raciocínio, o North American Serials Interest Group ressaltou a importância da experiência, uma vez que o trabalho em bibliotecas digitais muitas vezes não é feito por profissionais iniciantes, e os empregadores tendem a associar anos de experiência com as competências que se identificam em editais de emprego. Ressalte-se a importância da competência "experiência" com o pensamento, nesta linha, do psicólogo John Dewey e o quesito aprendizado longo vida.

O artigo também levantou que o mercado pede PI com competências pessoais, tecnológicas, que buscam atualização e fazem treinamentos, e desenvolvem habilidades financeiras, para observar e gerir a organizacional e gestão de recursos humanos.

\begin{tabular}{l|l|l|l|l|l|l|} 
(C) Rev. Digit.Bibliotecon. Cienc. Inf. & Campinas, SP & v.14 & n.3 & p.426-449 & set/dez. 2016 & ISSN 1678-765X \\
\hline
\end{tabular} 
Duas perguntas que acompanharam o artigo foram: como garantir a permanência das bibliotecas digitais? De que maneira se pode afiançar que o grande volume de informação digital gerado, nos mais variados formatos, estará disponível e plenamente passível de uso ao longo do tempo? Para responder lembramos que o Brasil ainda carece de cursos sobre práticas de PD. Tais estudos que provêm capacitação digital devem não apenas abranger a área da tecnologia, visando ajudar a operacionalizar a guarda e recuperação da informação em formato digital, mas também treinar outros profissionais, como os da informação, em princípio mais habilitados a fazer a análise técnica da informação e, assim, alimentar as bases de dados documentais com metadados.

É certo que os PI devem ter competências digitais que venham a ajudá-los a desempenhar melhor sua atividade profissional, mas também é apropriado lembrar que tais capacidades são melhor alcançadas e mantidas com a chamada aprendizagem ao longo da vida, busca e produção intermitente dos novos conhecimentos.

Vivemos um período de transição, alguns autores, há tempos, informam que o trabalho do PI está mudando, e que ele deve buscar e assumir novas competências. No entanto, em nível nacional, estes mesmos autores ainda não explicitaram quais seriam estas competências. Em estudos internacionais a temática já está mais amadurecida, como mostramos, e começam a elencar algumas destas competências para o profissional do mundo digital.

A literatura ainda mostra variadas formas de nomear o PI digital como data librarian, data curator, data manager, eScience professionals, cientista de dados, gestor de dados, entre muitos outros títulos. Falta também a definição sobre quem estará adiante das unidades de informação digitais, gerindo-as, se bibliotecários, se o pessoal de TI (computação), se arquivistas, enfim, muitos são os habilitados. Quem sabe o futuro virá, como sugere o National Science (2009), com a colaboração entre as organizações, entidades e pessoas para levar adiante a gestão e responsabilidade pela preservação e curadoria de dados digitais.

Embora o núcleo da profissão da informação continue a ser o mesmo, os métodos e ferramentas para a entrega de informação precisam mudar e se expandir. Apesar de manter seu usuário e sua abordagem centrados no conteúdo, os profissionais demandam cada vez mais conhecimento avançado de tecnologia da informação para implantar seu pleno potencial. Continuamente devem buscar oportunidades para impulsioná-los, preparando os PI para sua recuperação mais avançada, interpretação, síntese, desenvolvimento de produtos e serviços virtuais em uma escala global. Os profissionais da informação que trabalham com tecnologia têm as suas raízes no passado, mas precisam vislumbrar o futuro. As competências levantadas aqui são a base para o crescimento na era da informação. Os PI devem reconhecer e abraçar a natureza em expansão do campo tecnológico e os desafios que enfrentam. Importante não esquecer que o sucesso estará ao lado da escolha que trouxer uma vida profissional feliz. 


\section{REFERÊNCIAS}

ABBOT, Daisy. What is digital curation. Edinburgh, UK: Digital Curation Center, 2008. Disponível em <http://www.era.lib.ed.ac.uk/ bitstream/1842/3362/1/Abbott\%20What\%20is\%20digital\%20curation_\%20_\%20Digital\%20 Curation\%20Centre\%234291.html> Acesso em 30 jan. 2013.

ABBOTT, Andrew. The information professions. In: ABBOTT, Andrew. The system of professions: an essay on the division of expert labor. Chicago: University of Chicago Press, 1988. p. 215-246.

ALBERNAZ, Claudia Borges Lima. O secretário executivo como gatekeeper da informação. 2011. 381 f. Tese (Doutorado em Ciência da Informação) — Universidade de Brasília, Brasília, 2011.

AMARAL, Sueli Angélica do (Org). Marketing na Ciência da Informação. Brasília: Editora Universidade de Brasília, 2007. 230p.

ALLARD, S.; MACK, T.R.; FELTNER-REICHERT, M. The librarian's role in institutional repositories: A content analysis of the literature. Reference Services Review, v. 33, n. 3, p. 325-336, 2005. DOI:10.1108/00907320510611357

BAZIN, Patrick. Prefácio. In: ACCART, Jean-Philippe. Serviço de referência: do presencial ao virtual. Brasília: Briquet de Lemos, 2012.

BENDASSOLLI, Pedro F.; BORGES-ANDRADE, Jairo Eduardo; MALVEZZI, Sigmar. Paradigmas, eixos temáticos e tensões na PTO no Brasil. Estudos de Psicologia, Natal, v. 15, n. 3, p. 281-289, dez. 2010. Disponível em:

$<$ http://www.scielo.br/scielo.php?script=sci_arttext\&pid=S1413-

294X2010000300008\&lng=en\&nrm=iso>. Acesso em 22 nov. 2013.

BORGES, Lívia de Oliveira; YAMAMOTO, Oswaldo H. IN: ZANELLI, J. C.; BORGESANDRADE, J. E.; BASTOS, A. V. B. (Org.). Mundo do trabalho: construção histórica e desafios contemporâneos. São Paulo: Artmed, 2014.

BORGES-ANDRADE, J. E.; PAGOTTO, C. P. O estado da arte e da pesquisa brasileira em Psicologia do Trabalho e das Organizações. Psicologia: Teoria e Pesquisa, 26 v. especial, p. 37-50, 2010.

BRANDÃO, Hugo Pena. Aprendizagem, contexto, competência e desempenho: um estudo multinivel. 2009. xi, 345, il. Tese (Doutorado em Psicologia Social, do Trabalho e das Organizações) - Universidade de Brasília, Brasília, 2009.

BRANDÃO, Hugo Pena; BORGES-ANDRADE, Jairo Eduardo. Causas e efeitos da expressão de competências no trabalho: para entender melhor a noção de competência. Revista de Administração Mackenzie, São Paulo, v. 8, n. 3, 2007, p. 32-49, 2007. 
Bueno, Danilo André. Mapeamento de fluxos documentais como elemento de identificação arquivística no âmbito da gestão de documento. 2013. 139 f. Dissertação (Mestrado em Ciência da Informação) Universidade Federal Fluminense, Instituto de Arte e Comunicação Social, 2013.

CCSDS. Reference model for an open archival information system (OAIS): recommended practice. Magenta Book, junho 2012. Disponível em:

<http://public.ccsds.org/publications/archive/650x0m2.pdf >. Acesso em 2 março de 2015.

CLATIN Marianne; FAUDUET, Louise; OURY, Clément; TRAMONI Jean-Philippe. Digital curators at work: analyzing emerging professional identities at the Bibliothèque Nationale de France (BnF). IFLA Conference, Lyon, 2014. Disponível em: http://library.ifla.org/934/1/209-clatin-en.pdf Acesso em 20 de junho de 2016.

CUNHA, Murilo Bastos da. Bibliografia sobre o fluxo do documento na biblioteca digital. DataGramaZero, Rio de Janeiro, v. 10, n. 5, out. 2009. Disponível em: http://www.dgz.org.br/out09/Art_01.htm Acesso em: 15 setembro de 2015.

DEWEY, John. Como pensamos: como se relaciona o pensamento reflexivo com o processo educativo, uma reexposição. 4. ed. São Paulo: Nacional, 1979.

DURAND, T. L'alchimie de la compétence. Revue Française de Gestion, n. 127, p. 84-102, 2000. Disponível em: <http://www.cmi-strategies.com/wp-content/uploads/2012/05/ThomasDurand-Alchemy-of-competence.pdf $>$. Acesso em 6 de fevereiro de 2013.

FARIA, Ana Carolina Cintra. A inserção do bibliotecário no mercado de trabalho: fatores de influência e competências. 2015. xi, 128 f, il. Dissertação (Mestrado em Ciência da Informação) - Universidade de Brasília, Brasília, 2015.

FARIA, Ana Carolina Cintra; CASTRO FILHO, Cláudio Marcondes de. Profissional da informação: estudo dos egressos no estado de São Paulo, mundo do trabalho, habilidades e competências. Ponto de Acesso, Salvador, v. 8, n. 3, p. 44-63, dez. 2014.

FERREIRA, Miguel. Introdução à Preservação Digital: conceitos, estratégias e actuais consensos. Guimarães, Portugal: Escola de Engenharia da Universidade do Minho, 2006. Disponível em: 〈http://repositorium.sdum.uminho.pt/bitstream/1822/5820/1/livro.pdf $>$. Acesso em 23 de fevereiro de 2013.

FRASER-ARNOTT, Melissa. Library and Information Science (LIS) Transferable Competencies. Partnership: Canadian Journal of Library and Information Practice and Research, v. 8, n. 2, 2013. Disponível em: <https://journal.lib.uoguelph.ca/index.php/perj/article/view/2595/2987\#.Vj_oererSt8>. Acesso em: 20 de abril de 2013.

GAMA, Ana Claudia Soares Cavalcante. Competência informacional: aprendizado individual ao longo da vida. 2013. 509 f., il. Tese (Doutorado em Ciência da Informação) Universidade de Brasília, Brasília, 2013. 
GONDIM, Sonia Maria Guedes; BORGES-ANDRADE, Jairo Eduardo; BASTOS, Antonio Virgílio Bittencourt. Psicologia do Trabalho e das Organizações: Produção Científica e Desafios Metodológicos. Psicologia em Pesquisa, Juiz de Fora, v. 4, n. 2, p. 84-99, julhodezembro de 2010.

GOODE, William J. Community within a Community: The Professions. American Sociological Review, v. 22, n. 2, abr., 1957, p. 194-200. Disponível em:

<http://www.jstor.org/stable/2088857>. Acesso em 5 de setembro de 2014.

HEDSTROM, Margaret. Digital Preservation: A Time Bomb for Digital Libraries. Computers and the Humanities, v. 31, p. 189-202, 1998. Disponível em: $<$ http://deepblue.lib.umich.edu/bitstream/handle/2027.42/42573/10579_2004_Article_15 3071.pdf;jsessionid=5395F9215FE2F1173FBD31FE3C55361A? sequence=1 >. Acesso em: 30 jun. 2012.

INTERNATIONAL FEDERATION OF LIBRARIES ASSOCIATION. IFLA SUBMISSION to EU Copyright Consultation now available online. 12 de março de 2014. Disponível em: <http://www.ifla.org/node/8437>. Acesso em 12 junho 2014.

JUDGE, Timothy A., KAMMEYER-MUELLER, John D. Job attitudes. Annual Review of Psychology, v. 63, p. 341-67, 2012. Disponível em:

<http://www.annualreviews.org/doi/abs/10.1146/annurev-psych-120710-100511>. Acesso em 3 de maio de 2014.

KIM, Jeonghyun; WARGA, Edward; MOEN, William. Competencies Required for Digital Curation: An Analysis of Job Advertisements. International Journal of Digital Curation, v. 8, n. 1, p. 66-83, 2013. Disponível em:

<http://www.ijdc.net/index.php/ijdc/article/view/8.1.66/317> . Acesso em 24 de fevereiro de 2014.

KIM, Jeonghyun, WARGA, Edward, MOEN, William. Digital Curation in the Academic Library Job Market. Proceedings of the ASIST Annual Meeting, v. 49, n. 1. 2012.

LEFURGY, Bill. Analysis of Current Digital Preservation Policies: Archives, Libraries and Museums. Washington, 2013. Disponível em:

<http://blogs.loc.gov/digitalpreservation/2013/08/analysis-of-current-digital-preservationpolicies-archives-libraries-and-museums/> . Acesso em 28 de abril de 2014.

LIMA, João Alberto de Oliveira. FRBR e bibliotecas digitais. Brasília: Universidade de Brasília, Faculdade de Ciência da Informação, Bibliotecas digitais, maio de 2015. Palestra para a disciplina Biblioteca digital em 29 de abril de 2015.

MÁRDERO ARELLANO, Miguel A. Critérios para a preservação digital da informação científica. 2008. 356 f. Tese (Doutorado em Ciência da Informação) - Universidade de Brasília, Brasília, 2008. Disponível em:

$<$ http://repositorio.bce.unb.br/bitstream/10482/1518/1/2008_MiguelAngelMarderoArellano.p df $>$. Acesso em 01 de junho de 2012. 
MÁRDERO ARELLANO, Miguel A. Preservação de documentos digitais. Ciência da Informação, Brasília, v. 33, n. 2, p. 15-27, 2004. Disponível em: $<$ http://www.scielo.br/scielo.php?pid=S0100-19652004000200002\&script=sci_arttext/>. Acesso em 25 de julho de 2012.

MUELLER, Suzana Pinheiro Machado. Perfil do bibliotecário, serviços e responsabilidades na área de informação e formação profissional. Revista de Biblioteconomia de Brasília, v. 17, n. 1, p. 63-70, jan./jun. 1989.

MUELLER, Suzana Pinheiro Machado. Uma profissão em evolução: profissionais da informação sob a ótica de Abbott - proposta de estudo. In: BAPTISTA, Sofia Galvão; MUELLER, Suzana Pinheiro Machado. (Org.). Profissional da informação: espaço de trabalho. Brasília: Thesaurus, 2004, p. 23-54.

NATIONAL SCIENCE AND TECHNOLOGY COUNCIL. Interagency Working Group on Digital Data. Harnessing the power of digital data for science and society. 2009. Disponível em: 〈http://www.nitrd.gov/about/harnessing_power_web.pdf $>$. Acesso em $30 \mathrm{de}$ abril de 2013.

NEIVA, Elaine Rabelo; CORRADI, Ariane Agnes. A Psicologia Organizacional e do Trabalho no Brasil: uma Análise a partir das Redes Sociais de Pesquisadores da PósGraduação. Revista Psicologia: Organizações e Trabalho, v. 10, n. 2, p. 67-84, jul/dez, 2010.

NORTH AMERICAN SERIALS INTEREST GROUP. Core Competencies for Electronic Resources Librarians 2013. NASIG website. 2015. Disponível em: $<$ http://www.nasig.org/uploaded_files/92/files/CoreComp/CompetenciesforPrintManagement final_ver_2015-5-30.pdf $>$. Acesso em 24 julho de 2015.

PALMER J.M.; BLAKE, C.L.; ALLARD, S. Interdisciplinary data Science education. In N. Xiao \& L. R. McEwen (Eds.), Special issues in data management. Washington, DC: American Chemical Society, 2012. (ACS Symposium Series, v. 1110). Disponível em: <http://pubs.acs.org/doi/abs/10.1021/bk-2012-1110.ch006>. Acesso em: 11 jun. 2015.

PORTER, Lyman W.; SCHNEIDER, Benjamin. What Was, What Is, and What May Be in OP/OB. Annual Review of Psychology, v. 1, p. 1-21, 2014. Disponível em: <http://www.annualreviews.org/doi/abs/10.1146/annurev-orgpsych-031413-091302>. Acesso em 11 de junho de 2014.

PORTICO. Archiving and Preserving e-Journals. 2015. Disponível em: <http://www.digitalpreservation.gov/partners/portico.html>. Acesso em 11 de junho de 2015.

ROSENTHAL, David S.; ROBERTSONI, Thomas; LIPKISII, Tom; REICHI, Vicky; MORABITO, Seth. Requirements for digital preservation systems: a bottom-up approach. $D$ Lib Magazine, v. 11, n. 11, Nov. 2005. Disponível em: <http://www.dlib.org/dlib/november05/rosenthal/11rosenthal.html $>$. Acesso em 28 jul. 2012.

SAYÃO, Luís Fernando; SALES, Luana Farias. Curadoria digital: um novo patamar para preservação de dados digitais de pesquisa. Informação \& Sociedade: Estudos, João Pessoa, v. 
22, n. 3, p. 179-191, set. /dez. 2012. Disponível em:

<www.ies.ufpb.br/ojs/index.php/ies/article/view/12224/8586>. Acesso em: 23 fev. 2013.

SILVA, Armando Malheiro. Arquivologia e gestão da informação/conhecimento. Informação \& Sociedade: Estudos, João Pessoa, v. 19, n. 2, 2009.

TIBBO, H.; HANK, C.; LEE, C. A. Challenges, curricula, and competencies: Researcher and practitioner perspectives for informing the development of a digital curation curriculum. In Archiving 2008, 24-27 June, 2008, Berna, Suíça. Final Program and Proceedings.

Springfield, VA: Society for Imaging Science and Technology. p. 234-238.

VALENTIM, Marta Ligia. Formação: competências e habilidades do profissional da informação. São Paulo: Polis, 2002.

WALTER, Maria Tereza Machado Teles. Bibliotecários no Brasil: representações da profissão. 2008. 345 f. Tese (Doutorado em Ciência da Informação) - Universidade de Brasília, Brasília, 2008.

ZARIFIAN, P. O modelo da competência: trajetória histórica, desafios atuais e propostas. São Paulo: SENAC/SP. 1999.
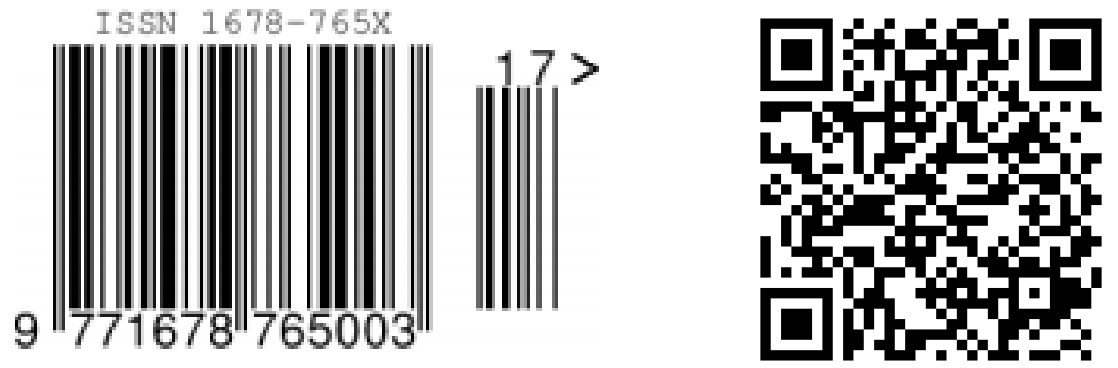